FACTA UNIVERSITATIS

Series: Mechanical Engineering Vol. 18, N 2 2, 2020, pp. 189 - 204

https://doi.org/10.22190/FUME200421022P

Original scientific paper

\title{
A CENTER MANIFOLD THEORY-BASED APPROACH TO THE STABILITY ANALYSIS OF STATE FEEDBACK TAKAGI-SUGENO-KANG FUZZY CONTROL SYSTEMS
}

\author{
Radu-Emil Precup ${ }^{1}$, Stefan Preitl ${ }^{1}$, Emil M. Petriu ${ }^{2}$, \\ Raul-Cristian Roman ${ }^{1}$, Claudia-Adina Bojan-Dragos ${ }^{1}$, \\ Elena-Lorena Hedrea ${ }^{1}$, Alexandra-Iulia Szedlak-Stinean ${ }^{1}$
}

${ }^{1}$ Politehnica University of Timisoara, Dept. Automation and Applied Informatics, Romania ${ }^{2}$ University of Ottawa, School of Electrical Engineering and Computer Science, Canada

\begin{abstract}
The aim of this paper is to propose a stability analysis approach based on the application of the center manifold theory and applied to state feedback TakagiSugeno-Kang fuzzy control systems. The approach is built upon a similar approach developed for Mamdani fuzzy controllers. It starts with a linearized mathematical model of the process that is accepted to belong to the family of single input secondorder nonlinear systems which are linear with respect to the control signal. In addition, smooth right-hand terms of the state-space equations that model the processes are assumed. The paper includes the validation of the approach by application to stable state feedback Takagi-Sugeno-Kang fuzzy control system for the position control of an electro-hydraulic servo-system.
\end{abstract}

Key Words: Center Manifold Theory, Electro-hydraulic Servo-systems, Stability Analysis, State Feedback Takagi-Sugeno-Kang Fuzzy Control Systems

\section{INTRODUCTION}

The systematic design and tuning of the fuzzy control systems is supported by analyses that include stability, controllability, observability, sensitivity and robustness. One of the main classical and modern topics in this regard is the stability analysis of the fuzzy control systems, which enable their stable design in the context of the model-based fuzzy control system design.

\footnotetext{
Received April 21, 2020 / Accepted June 30, 2020

Corresponding author: Radu-Emil Precup

Politehnica University of Timisoara, Department of Automation and Applied Informatics, Bd. V. Parvan 2, 300223 Timisoara, Romania

E-mail: radu.precup@aut.upt.ro 
The general approach to dealing with the stability analysis in the model-based fuzzy control, treated in the main woks [1-3], is to make use of Takagi-Sugeno-Kang fuzzy models of the process and express the stability analysis conditions as Linear Matrix Inequalities (LMIs) in terms of the parallel distributed compensation (PDC) approach, which states that the dynamics of each local subsystem in the rule consequents of the Takagi-Sugeno-Kang fuzzy models of the process is controlled using the eigenvalue analysis [2, 3]. Recent results on LMI-based stability analysis include the relaxation of stability conditions [4-11], the negative absolute eigenvalue approach [12] and the use of Lyapunov-Krasovskii functionals [13].

The main idea in relation with the PDC-based approach to the stability analysis and stable design of Takagi-Sugeno-Kang fuzzy control systems based on LMIs is an extensive use of quadratic Lyapunov function candidates. The effect of various parameters of the fuzzy models are considered resulting in non-quadratic Lyapunov function-based approaches as, for example, the membership-function-dependent analysis [14,15], non-quadratic stabilization of uncertain systems, exponential stability with guaranteed cost control [16], piecewise continuous and smooth functions, piecewise continuous exact fuzzy models, general polynomial approaches [17, 18], sum-of-squares-based polynomial membership functions [19-22], superstability conditions, integral structure based Lyapunov functions [23], the subspace-based improved sector nonlinearity approach [24], the fractional intelligent approach, and interpolation function-based approaches [25].

The presented short literature survey indicates, as shown in [26] and [27], that the classical approach based on PDC to stabilize fuzzy control systems and the use LMIs in the stability analysis may introduce computational burden, complexity and coupling of subsystems. Therefore, different approaches to LMI-based ones are justified; such also popular approaches include

- Bilinear Matrix Inequalities [28, 29],

- Popov's hyperstability theory [30-33],

- the limit cycle-based approach [34-36],

- the circle criterion [37-40];

- the harmonic balance method [31], [41-44], and,

- the center manifold theory [45].

Many of these non-LMI-based approaches work only with Mamdani fuzzy controllers and not with Takagi-Sugeno-Kang ones. A part of the authors' stability analysis approaches is mainly focused on Mamdani fuzzy controllers, avoiding LMI formulation and solving; it is built around LaSalle's invariant set principle [46], Barbashin-Krasovskii theorem [47], the use of quadratic Lyapunov function candidates formulated for discrete-time systems [48], and the popular Lyapunov's direct method [49, 50]. Some of these approaches also work with Takagi-Sugeno-Kang fuzzy controllers, but many stability analysis approaches are formulated for continuous-time systems and since the real-world implementation of fuzzy controllers is carried out as digital controllers, there is a real need to either develop stability analysis approaches formulated for discrete-time systems or to transfer the continuous-time approaches to discrete-time ones (which is not a simple task).

Several alternative approaches to fuzzy control have been recently developed. All of them require the systematic design assisted by appropriate stability analysis approaches.

A representative alternative approach to the traditional fuzzy systems is represented by type-2 fuzzy systems, with the ability to better capture nonlinear mechanisms in dynamic 
systems compared to the classical type-1 fuzzy systems. The additional parameters of these nonlinear systems offer increased flexibility (advantageous in case of optimal fuzzy control) but this is paid by their more complicated design and tuning if they are used as fuzzy models and controllers. Some of the important applications of type-2 fuzzy systems to fuzzy control with stability analysis and nature-inspired algorithms that ensure their optimal tuning are reported in [14, 16, 33] and [51-54].

A special type of fuzzy systems with nonparametric vectorized antecedents has been proposed by Angelov and Yager [55, 56], and is referred to as AnYa. Initially supported by the concept of granules, AnYa is based on data clouds, which are sets of previous data samples close to each other, and the membership degrees are computed using the relative data density of the current data with the existing cloud. The data clouds are used, similar to the classical data clusters, in partitioning the problem space to detect different operational (nonlinear) conditions in the context of systems modeling and identification. But data clouds do not require an explicit definition of the membership functions, and they do not have or require boundaries; therefore, they do not have specific shapes. Several applications of AnYa systems to control and modeling are reported in [57-60].

AnYa systems can evolve their structure by adding new data clouds. This relates them to evolving fuzzy systems. As shown in [61], the concept of evolving fuzzy systems was coined by P. Angelov back in 2001 and further developed in his later works [62-66]. The specific feature of these systems is the computation of the rule bases by a learning process, i.e. conducting continuous online rule base learning, with some recent results given in [67-69]. The stability analysis of systems based on AnYa and evolving fuzzy controllers is an important subject.

As pointed out in [27], another alternative approach is represented by Tensor Product (TP)-based model transformation, as a numerical method capable of transforming the Linear Parameter-Varying (LPV) dynamic models into parameter-varying weighted combination of parameter independent (constant) system models under the form of Linear Time-Invariant (LTI) systems. The TP models are originally polytopic structures, where LTI systems are the vertex models of a convex hull of the model; they may be relatively far from any linearized operation points. In the case of TP models an LTI system affects the whole operation domain, not just a local area as in case of fuzzy systems, but according to the weighting functions, which actually replace the membership functions of fuzzy systems. Representative applications of TP-based model transformation to modeling and control are discussed in [70-76].

In contrast to model-based control, data-driven control or data-based control avoids the system (process) identification by constructing controllers directly from data without identifying a system model. That is the reason why data-driven control is also referred to as model-free control, i.e. model-free in controller tuning. Stability analysis is also treated in the date-driven or data-based control, but it is difficult to carry out this analysis if process models are avoided. A useful discussion on model-based versus data-driven control, that inspires future research directions, is presented in [77]. Unlike much of the existing work, as, for example [78-80], the fresh paper [81] does not make the a priori assumption of persistency of excitation on the input; instead, it studies necessary and sufficient conditions on the given data under which different analysis and control problems can be solved; thus it reveals situations in which a controller can be tuned from data even though unique system identification is impossible. 
The model-free tuning of fuzzy controllers is an alternative approach to the modelbased design of these controllers in order to benefit from the advantages of data-driven control and fuzzy control and to mitigate, if possible, their shortcomings. The indirect model-free tuning of fuzzy controllers has initially been proposed and applied in [82-84], and continued in [85-87] by structures that combine data-driven control and fuzzy control in order to incorporate model-free features in novel fuzzy control system structure. Thus, steps forward towards direct model-free tuning of fuzzy controllers are currently taken.

Starting with the center manifold theory approach to the stability analysis of fuzzy control systems with Mamdani fuzzy controllers suggested in [45], this paper highlights the center manifold theory approach as a version to stability analysis and next stable design of fuzzy controllers. In this regard the paper is focused on state feedback TakagiSugeno-Kang fuzzy controllers. The presentation is focused on second-order input-affine nonlinear systems and the application is done on a state feedback controller for an electrohydraulic servo system.

The paper treats the following topics: the process models are presented in the next section. Section 3 describes the center manifold approach to stability analysis of fuzzy control systems. The application of the stability analysis approach to the state feedback position control of an electro-hydraulic servo system is carried out in Section 4. The conclusions are pointed out in Section 5.

\section{PROCESS MODELS}

The dynamics of the process is described by the state-space equation of an input-affine nonlinear dynamical system

$$
\dot{\mathbf{x}}_{P}=\mathbf{f}\left(\mathbf{x}_{P}\right)+\mathbf{b} u,
$$

where $\mathbf{x}_{P}=\left[\begin{array}{llll}x_{P 1} & x_{P 2} & \ldots & x_{P n}\end{array}\right]^{T} \in \mathfrak{R}^{n}$ is the state vector, $\mathbf{b}$ is an $n \times 1$ dimensional column matrix of constant parameters, $u \in \mathfrak{R}$ is the control signal, $\mathbf{f}: \mathfrak{R}^{n} \rightarrow \mathfrak{R}^{n}$ is the process function and $T$ indicates matrix transposition. The only constraint imposed to $\mathbf{f}$ is that it must be a smooth function.

For the sake of simplicity, as shown in [45], the formulations given as follows will be particularized to second-order $(n=2)$ input-affine nonlinear systems. Therefore, Eq. (1) is transformed into

$$
\begin{aligned}
& \dot{x}_{P 1}=f_{1}\left(x_{P 1}, x_{P 2}\right)+b_{1} u, \\
& \dot{x}_{P 2}=f_{2}\left(x_{P 1}, x_{P 2}\right)+b_{2} u,
\end{aligned}
$$

where $f_{1}, f_{2}: \mathfrak{R}^{2} \rightarrow \mathfrak{R}$ are smooth scalar functions, and $b_{1}, b_{2}=$ const $\in \mathfrak{R}$. A coordinate transformation is next applied, which depends on the values of $b_{1}$ and $b_{2}$, and the state-space equations in (2) become

$$
\begin{aligned}
& \dot{x}_{1}=g_{1}\left(x_{1}, x_{2}\right), \\
& \dot{x}_{2}=g_{2}\left(x_{1}, x_{2}\right)+u,
\end{aligned}
$$

where $g_{1}, g_{2}: \mathfrak{R}^{2} \rightarrow \mathfrak{R}$ are smooth scalar functions, and the new (transformed) state variables are $x_{1}$ and $x_{2}$. 
The simplified models given in (2) are justified because many processes can be transformed to such models by model order reduction. In addition, several models as those specific to sliding mode control and model-free control can be expressed so as to depend on the control error and its derivative as state variables and the rest of nonmodeled process dynamics plays the role of a disturbance term.

Since the free response is analyzed, i.e. the local asymptotical stability of the control system around the origin $(0,0)$ is analyzed, zero reference input is next considered. The following state feedback control law is applied:

$$
u=-g_{2}\left(x_{1}, x_{2}\right)-k_{1} x_{1}-k_{2} x_{2}-h\left(x_{1}, x_{2}\right),
$$

where $k_{1}, k_{2}=$ const $\in \mathfrak{R}$ are the linear state feedback gains and the nonlinear state feedback smooth function $h: \mathfrak{R}^{2} \rightarrow \mathfrak{R}$ has the features

$$
h(0,0)=0, \mathrm{~d} h(0,0)=0 .
$$

Using (5) in (3), the closed-loop state feedback control system will be characterized by the state equations

$$
\begin{aligned}
& \dot{x}_{1}=g_{1}\left(x_{1}, x_{2}\right), \\
& \dot{x}_{2}=-k_{1} x_{1}-k_{2} x_{2}-h\left(x_{1}, x_{2}\right),
\end{aligned}
$$

which are next linearized at the origin $(0,0)$ leading to the linearized state equations

$$
\begin{aligned}
& \dot{x}_{1}=\frac{\partial g_{1}}{\partial x_{1}}(0,0) x_{1}+\frac{\partial g_{1}}{\partial x_{2}}(0,0) x_{2}, \\
& \dot{x}_{2}=-k_{1} x_{1}-k_{2} x_{2} .
\end{aligned}
$$

In order to carry out the feedback stabilization, the state feedback fuzzy control is a particular case of the general problem defined in [88], it is required that [45], [89]

$$
\frac{\partial g_{1}}{\partial x_{1}}(0,0)=\frac{\partial g_{1}}{\partial x_{2}}(0,0)=0
$$

in addition, for the sake of simplicity [45]

$$
k_{2}=1
$$

and the higher order terms in the Taylor series expansion of $g_{1}$ and $h$ must depend only on $x_{1}$.

\section{STABILITY ANALYSIS APPROACH}

Using the assumptions presented in the previous section and expressing the Taylor series expansions of $g_{1}$ and $h$, the introduction of the coordinate transformation [45]

the center manifold is

$$
\begin{aligned}
& x_{1}^{*}=x_{1}, \\
& x_{2}^{*}=x_{2}+k_{1} x_{1},
\end{aligned}
$$




$$
x_{2}^{*}=\varphi\left(x_{1}^{*}\right) .
$$

Computing a second-order approximation of $\varphi$ according to [89] in terms of (10), the local asymptotic stability conditions are [45]

$$
\begin{aligned}
& \frac{\partial^{2} g_{1}}{\partial x_{1}^{2}}(0,0)-k_{1} \frac{\partial^{2} g_{1}}{\partial x_{1} \partial x_{2}}(0,0)=0, \\
& \frac{\partial^{2} g_{1}}{\partial x_{1}^{2}}(0,0)-\frac{\partial^{2} g_{1}}{\partial x_{1} \partial x_{2}}(0,0) \frac{\partial^{2} h}{\partial x_{1} \partial x_{2}}(0,0)<0,
\end{aligned}
$$

where the conditions in (12) hold for

$$
\frac{\partial^{2} g_{1}}{\partial x_{1}^{2}}(0,0) \neq 0 .
$$

Equations (12) and (13) are next processed resulting in the stability condition [45]

$$
\frac{\partial^{2} g_{1}}{\partial x_{1}^{2}}(0,0)\left[k_{1}-\frac{\partial^{2} h}{\partial x_{1} \partial x_{2}}(0,0)\right]<0 \text {. }
$$

The stability analysis approach is formulated accepting nonlinear input-output static map $F$ of the fuzzy controller

$$
u=F(\mathbf{i}),
$$

where $\mathbf{i}$ is the input vector

$$
\mathbf{i}=\left[\begin{array}{l}
i_{1} \\
i_{2}
\end{array}\right]=\mathbf{T}\left[\begin{array}{l}
r \\
\mathbf{x}
\end{array}\right]
$$

with $\mathbf{T}-$ a $2 \times 3$-dimensional constant transformation matrix that is not necessarily set and $r-$ the reference input.

The stability analysis approach consists of the following steps also given in [45] but with a different step 2:

Step 1 The necessary coordinate transformations are done.

Step 2 Input-output static map $F$ of the fuzzy controller is approximated to achieve the control law in Eq. (4). Two approaches can be used in this regard:

- approximation of triangular and trapezoidal membership functions with exponential functions [90] or using approximation approaches transferred from PIand PID-fuzzy controllers,

- least-squares fitting by the proper definition of an optimization problem and its solving by classical [91-94] or nature-inspired [95-98] optimization algorithms.

Step 3 The stability conditions (8), (9), (13) and (14) are checked. Their fulfillment guarantees the local asymptotic stability. 


\section{VALIDATION ON ELECTRO-HydRAULIC SERVO SYSTEM POSITION CONTROL}

The validation of the stability analysis approach given in the previous section is done, as in [45], in terms of the state feedback control system structure applied to the position control of an Electro-Hydraulic Servo system (EHS) with the block diagram presented in Fig. 1. The blocks and variables in Fig. 1 are [99]: NL 1 ... NL 5 - technological nonlinearities, EHS electro-hydraulic converter, SVD - the slide-valve distributor, MSM - main servo motor, M 1 and M 2 - measuring instrumentation, $u$ - control signal, $y$ - controlled output, $x_{1}$ and $x_{2}-$ state variables, $x_{1 M}$ and $x_{2 M}$ - measured state variables. The values of all parameters of EHS are [99], [100]: $u_{l}=10 \mathrm{~V}, g_{0}=0.0625 \mathrm{~mm} / \mathrm{V}, \varepsilon_{2}=0.02 \mathrm{~mm}, \varepsilon_{4}=0.2 \mathrm{~mm}, x_{1 l}=21.8 \mathrm{~mm}, y_{l}$ $=210 \mathrm{~mm}, T_{i 1}=0.001872 \mathrm{~s}, T_{i 2}=0.0756 \mathrm{~s}, k_{M 1}=0.2 \mathrm{~V} / \mathrm{mm}, k_{M 2}=0.032 \mathrm{~V} / \mathrm{mm}$. The three steps of the stability analysis approach are applied as follows.

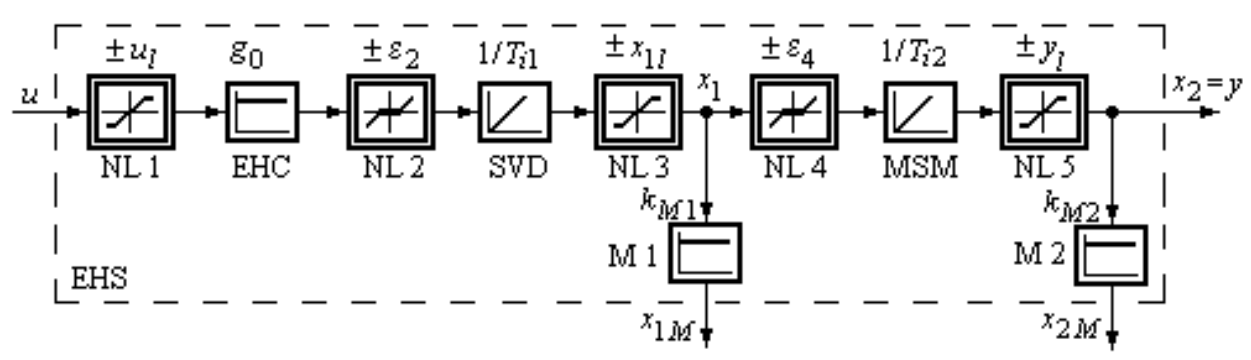

Fig. 1 Block diagram of electro-hydraulic servo system viewed as controlled process [99]

In Step 1, due to very large parametric insensitivity and large linear domains of NL 1, NL 3 and NL 5, in the conditions of small variations of the variables, omitting the nonlinearities in Fig. 1 leads to the simplified state equations of the process [45]

$$
\begin{aligned}
& \dot{x}_{1 M}=b^{*} u, \\
& \dot{x}_{2 M}=a x_{1 M},
\end{aligned}
$$

with the parameter values $a=14.05$ and $b^{*}=26.04$.

Using $x_{P 1}=x_{1 M}$ and $x_{P 2}=x_{2 M}$ in Eq. (17), a simple linear state transformation leads to the state-space equations of the process given in Eq. (3), where

$$
g_{1}\left(x_{1}, x_{2}\right)=a^{*} x_{1}, g_{2}\left(x_{1}, x_{2}\right)=0,
$$

with $a^{*}=a b^{*}=365.862$.

Since $y=x_{2 M}$, the fuzzy control system structure is illustrated in Fig. 2, where $r-$ reference input, $e$ - control error, $i_{1}$ and $i_{2}$ - fuzzy controller inputs also given in (16), and

$$
\begin{aligned}
& i_{1}=x_{1 M}, \\
& i_{2}=r-x_{2 M} .
\end{aligned}
$$




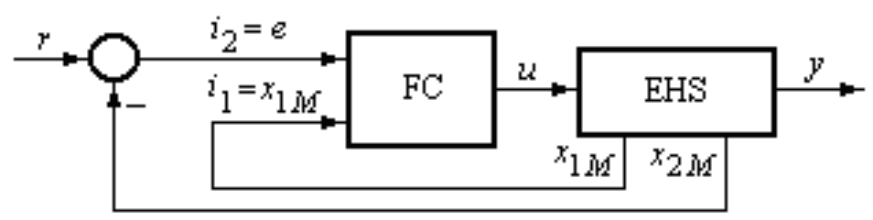

Fig. 2 State feedback fuzzy control system

The block FC in Fig. 2 is a Takagi-Sugeno-Kang state feedback fuzzy controller, which is designed starting with a set of linear state feedback controllers to stabilize the simplified EHS model in (17) and next applying the modal equivalence principle [101] to merge the linear state feedback controllers placed in the rule consequents of FC. The disturbance input is not introduced in Figs. 1 and 2 because, as specified in the previous sections, stabilization is targeted; reference tracking and disturbance rejection are not objectives of this paper.

In Step 2, as pointed out in [102], cosine-type membership functions for the linguistic terms of the input and also scheduling variables are considered to be convenient in the analysis of FC. Such membership functions are set, and they are shown in Fig. 3. Fig. 3 points to the parameters of the input membership functions, $B_{1}>0$ and $B_{2}>0$.

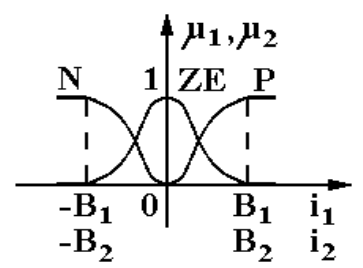

Fig. 3 Input membership functions [102]

Using Eq. (19) with $r=0$, the state-space equations of EHS as controlled process are

$$
\begin{aligned}
& \dot{i}_{1}=b^{*} u, \\
& \dot{i}_{2}=-a^{*} i_{1} .
\end{aligned}
$$

In Step 3, the local asymptotic stability is analyzed as follows with $i_{1}$ and $i_{2}$ instead of $x_{1}$ and $x_{2}$, respectively, on the basis of the results given in Sections 2 and 3. The state feedback control law is expressed in terms of Eq. (4). Use is made of Eq. (19), and the modified control law is [45]

$$
u=k_{1} i_{1}+k_{2} i_{2}-h\left(i_{1}, i_{2}\right),
$$

where $k_{1}=1$, and $k_{2}$ is set to $k_{2}=1+a^{*}=366.862$ in order to fulfill the stability condition (8). The stability condition (14) is thus transformed into [45]

$$
k_{1}>\frac{\partial^{2} h}{\partial i_{1} \partial i_{2}}(0,0) \text {. }
$$


The stability condition (22) is related to relatively small modifications of the nonlinear part of the control law. That is the reason why function $h$ has to be a smooth one to be produced by the fuzzy controller; therefore, the rule base of FC will be derived as follows in this regard.

Three linear state feedback controllers are first designed, and they will be next placed as local controllers in the rule consequents of FC. Imposing the linear closed-loop control system poles

$$
p_{1,2}^{*(i)}=-p^{(i)} \pm j q^{(i)},
$$

with $p^{(i)}>0$ and $q^{(i)} \geq 0$, and the superscript $(i)$ indicates the index of the linear state feedback controller (or the local controller), $i=1 \ldots 3$, expressed as

$$
u^{(i)}=k_{1}^{(i)} i_{1}+k_{2}^{(i)} i_{2},
$$

the classical pole placement approach leads to local controller gains $k_{1}^{(i)}$ and $k_{2}^{(i)}$

$$
k_{1}^{(i)}=-\frac{2 p^{(i)}}{b^{*}}, k_{2}^{(i)}=\frac{\left(p^{(i)}\right)^{2}+\left(q^{(i)}\right)^{2}}{a^{*} b^{*}}, i=1 \ldots 3 .
$$

The first local controller, i.e. $i=1$ in (24), is that situated at the biggest distance to the zero control signal line

$$
u-k_{1} i_{1}+k_{2} i_{2}=0
$$

in the plane $\left\langle i_{1}, i_{2}\right\rangle$. This local linear state feedback control system is imposed to be the most oscillatory but also fastest one in terms of

$$
p^{(1)}=2 p, q^{(1)}=2 p \sqrt{3},
$$

where $p>0$ is a design parameter that affects the dynamics of the fuzzy control system.

The second local controller, i.e. $i=2$ in Eq. (24), is that situated at the average distance to the zero control signal line in (26). This local linear state feedback control system is also imposed to be oscillatory but with a smaller overshoot and larger settling time by imposing

$$
p^{(2)}=p, q^{(2)}=p \text {. }
$$

The third local controller, i.e. $i=3$ in (24), is that situated exactly on the zero control signal line in Eq. (26). This local linear state feedback control system is imposed to be aperiodic with an average settling time compared to the first two local control systems because of imposing

$$
p^{(3)}=2 p, q^{(3)}=0 \text {. }
$$

Using the information given before, the rule base of the Takagi-Sugeno-Kang state feedback fuzzy controller is obtained by merging the three local linear state feedback controllers in (24) and placing them in the rule consequents. The rule base is presented in Table 1. 
Table 1 Rule base of Takagi-Sugeno-Kang fuzzy controller

\begin{tabular}{ccccc}
\hline & & \multicolumn{3}{c}{$i_{1}$} \\
\cline { 3 - 5 } & & $\mathrm{N}$ & $\mathrm{ZE}$ & $\mathrm{P}$ \\
\hline \multirow{3}{*}{$i_{2}$} & $\mathrm{P}$ & $u^{(3)}$ & $u^{(2)}$ & $u^{(1)}$ \\
& $\mathrm{ZE}$ & $u^{(2)}$ & $u^{(3)}$ & $u^{(2)}$ \\
& $\mathrm{N}$ & $u^{(1)}$ & $u^{(2)}$ & $u^{(3)}$ \\
\hline
\end{tabular}

The FC block in Fig. 2 operates on the basis of the SUM and PROD operators in the inference engine and the weighted average method for defuzzification. This fuzzy controller structure allows for the determination of nonlinear term $h\left(i_{1}, i_{2}\right)$ in Eq. $(21)$.

As done in [45] and [100] for the Mamdani fuzzy control system, the following values of Takagi-Sugeno-Kang fuzzy controller parameters ensure the system stability: $B_{1}=0.5$, $B_{2}=1, p=3.5$. The stability tests of this state feedback Takagi-Sugeno-Kang fuzzy control system were done by digital simulation considering eight different nonzero initial conditions and $r=0$. The state trajectories illustrated in Fig. 3 give an indication on the system stability. The regulation and tracking performance of the fuzzy control system were not analyzed; however, the optimal tuning can be carried out in this context, with the results that can be quite different for this application and other challenging ones as well [103-108].

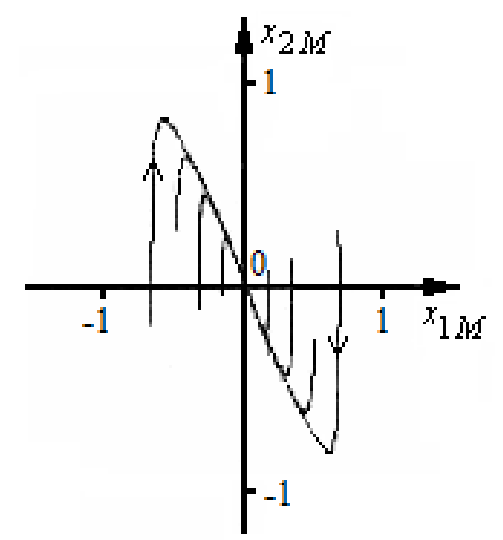

Fig. 4 State trajectories of state feedback Takagi-Sugeno-Kang fuzzy control system considering $r=0, x_{1 M}(\mathrm{~V}), x_{2 M}(\mathrm{~V})$

\section{CONCLUSIONS}

Starting with the authors' application of the center manifold theory to Mamdani fuzzy control systems, this paper suggests its application to state feedback Takagi-Sugeno-Kang fuzzy control systems as well. A three-step stability analysis is included in the paper as the main result, and an electro-hydraulic servo system application is treated.

The paper shows that the stability analysis is not complicated. However, several stability analysis conditions should be fulfilled. 
The main limitation of the presentation is that it is focused on second-order inputaffine nonlinear systems. The application to higher order systems is a challenge due to the possible difficult computation of the partial derivatives of fuzzy controller input-output static map $F$. This is one of the directions of future research in a strong relation with inclusion of several advantageous features specific to fuzzy systems [109-115] so as to modify the control system structure.

Another direction of future research is the stable fuzzy control system design. That requires the derivation of connections between the fuzzy controller parameters and the control system performance indices.

Nevertheless, the transition of the approach from continuous-time systems to discretetime ones aiming the real-time implementation is also targeted. However, the analysis of systems poles is needed, which is not simple in the context of LPV dynamic system models while avoiding the use of LMIs associated to PDC.

Acknowledgements: This work was supported by grants from the Ministry of Research and Innovation, CNCS - UEFISCDI, project numbers PN-III-P1-1.1-PD-2016-0331 and PN-III-P1-1.1PD-2016-0683, within PNCDI III, by the research grant GNaC2018 - ARUT, no. 1348/01.02.2019, financed by Politehnica University of Timisoara, and by the NSERC of Canada.

\section{REFERENCES}

1. Tanaka, K., Sugeno, M., 1992, Stability analysis and design of fuzzy control systems, Fuzzy Sets and Systems, 45(2), pp. 135-156

2. Wang, H.O., Tanaka, K., Griffin, M.F., 1996, An approach to fuzzy control of nonlinear systems: Stability and design issues, IEEE Transactions on Fuzzy Systems, 4(1), pp. 14-23.

3. Tanaka, K., Wang, H.O., 2001, Fuzzy Control Systems Design and Analysis: A Linear Matrix Inequality Approach, John Wiley \& Sons, New York, USA.

4. Wang, Z.-H., Liu, Z., Chen, C.L.P., Zhang, Y., 2019, Fuzzy adaptive compensation control of uncertain stochastic nonlinear systems with actuator failures and input hysteresis, IEEE Transactions on Cybernetics, 49(1), pp. 2-13.

5. Moodi, H., Farrokhi, M., Guerra, T.-M., Lauber, J., 2019, On stabilization conditions for T-S systems with nonlinear consequent parts, International Journal of Fuzzy Systems, 21(1), pp. 84-94.

6. Frezzatto, L., Lacerda, M.J., Oliveira, R.C.L.F., Peres, P.L.D., 2019, $\mathrm{H}_{2}$ and $\mathrm{H}_{\infty}$ fuzzy filters with memory for Takagi-Sugeno discrete-time systems, Fuzzy Sets and Systems, 371, pp. 78-95.

7. Gunasekaran, N., Joo, Y.H., 2019, Stochastic sampled-data controller for T-S fuzzy chaotic systems and its applications, IET Control Theory \& Applications, 13(12), pp. 1834-1843.

8. Sakthivel, R., Mohanapriya, S., Kaviarasan, B., Ren, Y., Anthoni, S.M., 2020, Non-fragile control design and state estimation for vehicle dynamics subject to input delay and actuator faults, IET Control Theory \& Applications, 14(1), pp. 134-144

9. Liu, D., Yang, G.-H., Er, M.J., 2020, Event-triggered control for T-S fuzzy systems under asynchronous network communications, IEEE Transactions on Fuzzy Systems, 28(2), pp. 390-399.

10. Shamloo, N.F., Kalat, A.A., Chisci, L., 2010, Indirect adaptive fuzzy control of nonlinear descriptor systems, European Journal of Control, 51, pp. 30-38.

11. Jiang, B.-P., Karimi, H.R., Kao, Y.-G., Gao, C.-C., 2020, Takagi-Sugeno model based event-triggered fuzzy sliding-mode control of networked control systems with semi-Markovian switchings, IEEE Transactions on Fuzzy Systems, 28(4), pp. 673-683.

12. Gandhi, R.V., and Adhyaru, D.M., 2010, Takagi-Sugeno fuzzy regulator design for nonlinear and unstable systems using negative absolute eigenvalue approach, IEEE/CAA Journal of Automatica Sinica, 7(2), pp. 482-493.

13. Xia, Y., Wang, J., Meng, B., Chen, X.-Y., 2020, Further results on fuzzy sampled-data stabilization of chaotic nonlinear systems, Applied Mathematics and Computation, 379, 125225, pp. 1-15. 
14. Lam, H.-K., 2018, A review on stability analysis of continuous-time fuzzy-model-based control systems: From membership-function-independent to membership-function-dependent analysis, Engineering Applications of Artificial Intelligence, 67, pp. 390-408.

15. Yang, X.-Z., Lam, H.-K., Wu, L.-G., 2019, Membership-dependent stability conditions for type-1 and interval type-2 T-S fuzzy systems, Fuzzy Sets and Systems, 356, pp. 44-62.

16. Pang, B., Liu, X., Jin, Q., Zhang, W., 2016, Exponentially stable guaranteed cost control for continuous and discrete-time Takagi-Sugeno fuzzy systems, Neurocomputing, 205(1), pp. 210-221.

17. Li, G.-L., Peng, C., Fei, M.-R., Tian, Y.-C., 2020, Local stability conditions for T-S fuzzy time-delay systems using a homogeneous polynomial approach, Fuzzy Sets and Systems, 385, pp. 111-126.

18. Xiao, B., Lam, H.-K., Yu, Y., Li, Y.-D., 2020, Sampled-data output-feedback tracking control for interval type2 polynomial fuzzy systems, IEEE Transactions on Fuzzy Systems, 28(3), pp. 424-433.

19. Yu, G.-R., Huang, Y.-C., Cheng, C.-Y., 2018, Sum-of-squares-based robust Hœ controller design for discretetime polynomial fuzzy systems, Journal of the Franklin Institute, 355(1), pp. 177-196.

20. Pang, B., Zhang, Q.-L., 2018, Interval observers design for polynomial fuzzy singular systems by utilizing sumof-squares program, IEEE Transactions on Systems, Man, and Cybernetics: Systems, DOI: 10.1109/TSMC.2018.2790975.

21. Zhao, Y.-X., He, Y.-X., Feng, Z.-G., Shi. P., Du, X., 2019, Relaxed sum-of-squares based stabilization conditions for polynomial fuzzy-model-based control systems, IEEE Transactions on Fuzzy Systems, 27(9), pp. 1767-1778.

22. Li, X.-M., Mehran, K., Lam, H.-K., Xiao, B., Bao, Z.-Y., 2020, Stability analysis of discrete-time positive polynomial-fuzzy-model-based control systems through fuzzy co-positive Lyapunov function with bounded control, IET Control Theory \& Applications, 14(2), pp. 233-243.

23. Yoneyama, J., 2017, New conditions for stability and stabilization of Takagi- Sugeno fuzzy systems, Proc. 2017 Asian Control Conference, Gold Coast, Australia, pp. 2154-2159.

24. Robles, R., Sala, A., Bernal, M., González, T., 2017, Subspace-based Takagi-Sugeno modeling for improved LMI performance, IEEE Transactions on Fuzzy Systems, 25(4), pp. 754-767.

25. Meda-Campaña, J.A., Grande-Meza, A., de Jesús Rubio, J., Tapia-Herrera, R., Hernández-Cortés, T., CurtidorLópez, A.V., Páramo-Carranza, L.A., Cázares-Ramírez, I.O., 2018, Design of stabilizers and observers for a class of multivariable TS fuzzy models on the basis of new interpolation function, IEEE Transactions on Fuzzy Systems, 26(5), pp. 2649-2662.

26. Guerra, T.M., and Vermeiren, L., 2001, Control laws for Takagi-Sugeno fuzzy models, Fuzzy Sets and Systems, 120(1), pp. 95-108.

27. Precup, R.-E., Hellendoorn, H., 2011, A survey on industrial applications of fuzzy control, Computers in Industry, 62(3), pp. 213-226.

28. Wu, H.-N., Feng, S., 2018, Mixed fuzzy/boundary control design for nonlinear coupled systems of ODE and boundary-disturbed uncertain beam, IEEE Transactions on Fuzzy Systems, 26(6), pp. 3379-3390.

29. Wu, H.-N., Zhang, X.-M., Wang, J.-W., Zhu, H.-Y., 2020, Observer-based output feedback fuzzy control for nonlinear parabolic PDE-ODE coupled systems, Fuzzy Sets and Systems, DOI: 10.1016/j.fss.2020.02.012.

30. Böhm, R., Bosch, M., 1995, Stabilitätsanalyse von Fuzzy-Mehrgrössenregelungen mit Hilfe der Hyperstabilitätstheorie, Automatisierungstechnik, 43(4), pp. 181-186.

31. Bindel, T., Mikut, R., 1995, Entwurf, Stabilitätsanalyse und Erprobung von Fuzzy-Reglern am Beispiel einer Durchflussregelung, Automatisierungstechnik, 43(5), pp. 249-255.

32. Precup, R.-E., Preitl, S., 1997, Popov-type stability analysis method for fuzzy control systems, Proc. Fifth European Congress on Intelligent Technologies and Soft Computing, Aachen, Germany, vol. 2, pp. 1306-1310.

33. Kumbasar, T., 2016, Robust stability analysis and systematic design of single-input interval type-2 fuzzy logic controllers, IEEE Transactions on Fuzzy Systems, 24(3), pp. 675-694.

34. Precup, R.-E., Preitl, S., Clep, P.A., Ursache, I.-B., Tar, J.K., Fodor, J., 2008, Stable fuzzy control systems with iterative feedback tuning, Proc. $12^{\text {th }}$ International Conference on Intelligent Engineering Systems, Miami, FL, USA, pp. 287-292.

35. Preitl, S., Precup, R.-E., Radac, M.-B., Dragos, C.-A., Tar, J.K., Fodor, J., 2008, On the stable design of stable fuzzy control systems with iterative learning control, Proc. $9^{\text {th }}$ International Symposium of Hungarian Researchers on Computational Intelligence and Informatics, Budapest, Hungary, pp. 345-360.

36. Radac, M.-B., Precup, R.-E., Preitl, S., Tar, J.K., Burnham, K.J., 2009, Tire slip fuzzy control of a laboratory anti-lock braking system, Proc. 2009 European Control Conference, Budapest, Hungary, pp. 940-945.

37. Aracil, J., Ollero, A., Garcia-Cerezo, A., 1989, Stability indices for the global analysis of expert control systems, IEEE Transactions on Systems, Man, and Cybernetics, 19(5), pp. 998-1007. 
38. Opitz, H.-P., 1993, Fuzzy control and stability criteria, Proc. First European Congress on Fuzzy and Intelligent Technologies, Aachen, Germany, vol. 1, pp. 130-136.

39. Ban, X.-J., Gao, X.Z., Huang, X.-L., Vasilakos, A.V., 2007, Stability analysis of the simplest Takagi-Sugeno fuzzy control system using circle criterion, Information Sciences, 177(20), pp. 4387-4409.

40. Haber Guerra, R.E., Schmitt-Braess, G., Haber Haber, R., Alique, A., Alique, J.R., 2003, Using circle criteria for verifying asymptotic stability in PI-like fuzzy control systems: application to the milling process, IEE Proceedings - Control Theory and Applications, 150(6), pp. 619-627.

41. Kiendl, H., 1993, Harmonic balance for fuzzy control systems, Proc. First European Congress on Fuzzy and Intelligent Technologies, Aachen, Germany, vol. 1, pp. 127-141

42. Boll, M., Bornemann, J., Dörrscheidt, F., 1994, Anwendung der harmonischen Balance auf Regelkreise mit unsymmetrischen Fuzzy-Komponenten und konstante Eingangsgrössen, Workshop "Fuzzy Control" des GMAUA 1.4.2, Dortmund, Forshungsberichte der Fakultät für Elektrotechnik, 0194, pp. 70-84.

43. Cuesta, F., Gordillo, F., Aracil, J., Ollero, A., 1999, Stability analysis of nonlinear multivariable Takagi-Sugeno fuzzy control systems, IEEE Transactions on Fuzzy Systems, 7(5), pp. 508-520.

44. Rosales, A., Ibarra, L., Ponce, P., Molina, A., 2019, Fuzzy sliding mode control design based on stability margins, Journal of the Franklin Institute, 356(10), pp. 5260-5273.

45. Precup, R.-E., Preitl, S., Solyom, S., 1999, Center manifold theory approach to the stability analysis of fuzzy control systems, in Computational Intelligence. Theory and Applications, Reusch, B., Ed., Springer-Verlag, Berlin, Heidelberg, New York, Lecture Notes in Computer Science, vol. 1625, pp. 382-390.

46. Tomescu, M.L., Preitl, S., Precup, R.-E., Tar, J.K., 2007, Stability analysis method for fuzzy control systems dedicated controlling nonlinear processes, Acta Polytechnica Hungarica, 4(3), pp. 127-141.

47. Precup, R.-E., Tomescu, M.L., Preitl, S., 2007, Lorenz system stabilization using fuzzy controllers, International Journal of Computers Communication and Control, 2(3), pp. 279-287.

48. Precup, R.-E., Tomescu, M.L., Preitl, S., Petriu, E.M., Dragos, C.A., 2011, Stability analysis of fuzzy logic control systems for a class of nonlinear SISO discrete-time systems, IFAC Proceedings Volumes, 44(1), pp. 13612-13617.

49. Precup, R.-E., Tomescu, M.-L., Dragos, C.-A., 2014, Stabilization of Rössler chaotic dynamical system using fuzzy logic control algorithm, International Journal of General Systems, 43(5), pp. 413-433.

50. Precup, R.-E., Tomescu, M.L., 2015, Stable fuzzy logic control of a general class of chaotic systems, Neural Computing and Applications, 26(3), pp. 541-550.

51. Navarro, G., Umberger, D.K., Manic, M. 2017, VD-IT2, Virtual Disk cloning on disk arrays using a type-2 fuzzy controller, IEEE Transactions on Fuzzy Systems, 25(6), pp. 1752-1764.

52. Rubio Solis, A., Melin, P., Martinez-Hernandez, U., Panoutsos, G., 2019, General type-2 radial basis function neural network: a data-driven fuzzy model, IEEE Transactions on Fuzzy Systems, 27(2), pp. 333-347.

53. Ramírez, E., Melin, P., Prado-Arechiga, G., 2019, Hybrid model based on neural networks, type-1 and type-2 fuzzy systems for 2-lead cardiac arrhythmia classification, Expert Systems with Applications, 126, pp. 295-307.

54. Moreno, J.E., Sanchez, M.A., Mendoza, O., Rodríguez Díaz, A., Castillo, O., Melin, P., Castro, J.R. 2020, Design of an interval type-2 fuzzy model with justifiable uncertainty, Information Sciences, 513, pp. 206-221.

55. Angelov, P., Yager, R., 2010, A simple fuzzy rule-based system through vector membership and kernel-based granulation, Proc. $5^{\text {th }}$ IEEE International Conference on Intelligent Systems, London, UK, pp. 349-354.

56. Angelov, P., Yager, R., 2011, Simplified fuzzy rule-based systems using non-parametric antecedents and relative data density, Proc. 2011 IEEE Workshop on Evolving and Adaptive Intelligent Systems, Paris, France, pp. 62-69.

57. Angelov, P., Škrjanc, I., Blažič, S., 2013, Robust evolving cloud-based controller for a hydraulic plant, Proc. 2013 IEEE Conference on Evolving and Adaptive Intelligent Systems, Singapore, pp. 1-8.

58. Škrjanc, I., Blažič, S., Angelov, P., 2014, Robust evolving cloud-based PID control adjusted by gradient learning method, Proc. 2014 IEEE Conference on Evolving and Adaptive Intelligent Systems, Linz, Austria, pp. $1-8$.

59. Blažič, S., Angelov, P., Škrjanc, I., 2015, Comparison of approaches for identification of all-data cloud-based evolving systems, IFAC-PapersOnLine, 48(10), pp. 129-134.

60. Škrjanc, I., Andonovski, G., Ledezma, A., Sipele, O., Iglesias, J.A., Sanchis, A., 2018, Evolving cloud-based system for the recognition of drivers' actions, Expert Systems with Applications, 99, pp. 231-238.

61. Precup, R.-E., Teban, T.-A., Petriu, E.M., Albu, A., Mituletu, I.-C., 2018, Structure and evolving fuzzy models for prosthetic hand myoelectric-based control systems, Proc. $26^{\text {th }}$ Mediterranean Conference on Control and Automation, Zadar, Croatia, pp. 625-630.

62. Angelov, P., Buswell, R.A., Wright, J.A., Loveday, E.L.,, 2001, Evolving rules-based control, Proc. EUNITE 2001 Symposium, Tenerife, Spain, pp. 36-41. 
63. Angelov, P., Buswell, R.A., 2002, Identification of evolving fuzzy rule-based models, IEEE Transactions on Fuzzy Systems, 10(5), pp. 667-677.

64. Angelov, P., 2002, Evolving Rule-Based Models: A Tool for Design of Flexible Adaptive Systems, SpringerVerlag, Heidelberg.

65. Angelov, P., Filev, D., 2002, Flexible models with evolving structure, Proc. 2002 First International IEEE Symposium on Intelligent Systems, Varna, Bulgaria, pp. 28-33.

66. Angelov, P., Filev, D., 2003, On-line design of Takagi-Sugeno models, in Fuzzy Sets and Systems - IFSA 2003, Bilgiç, T., De Baets, B., Kaynak, O., Eds. Springer-Verlag, Berlin, Heidelberg, Lecture Notes in Computer Science, vol. 2715, pp. 576-584.

67. Leite, D., Palhares, R.M., Campos, V.C.S., Gomide, F.A.C., 2015, Evolving granular fuzzy model-based control of nonlinear dynamic systems, IEEE Transactions on Fuzzy Systems, 23(4), pp. 923-938.

68. Lughofer, E., Pratama, M., 2018, Online active learning in data stream regression using uncertainty sampling based on evolving generalized fuzzy models, IEEE Transactions on Fuzzy Systems, 26(1), pp. 292-309.

69. Precup, R.-E., Teban, T.-A., Albu, A., Borlea, A.-B., Zamfirache, I.A., Petriu, E.M., 2020, Evolving fuzzy models for prosthetic hand myoelectric-based control, IEEE Transactions on Instrumentation and Measurement, 69(7), 1-12.

70. Baranyi, P., Korondi, P., Patton, R.J., Hashimoto, H., 2004, Trade-off between approximation accuracy and complexity for TS fuzzy models, Asian Journal of Control, 6(1), pp. 21-33.

71. Várkonyi, P., Tikk, D., Korondi, P., Baranyi, P., 2005, A new algorithm for RNO-INO type tensor product model representation, Proc. $9^{\text {th }}$ IEEE International Conference on Intelligent Engineering Systems, Mediterranean Sea, pp. 263-266.

72. Baranyi, P., Yam, Y., Varlaki, P., 2013, TP Model Transformation in Polytopic Model-Based Control, Taylor \& Francis, Boca Raton, FL.

73. Hedrea, E.-L., Bojan-Dragos, C.-A., Precup, R.-E., Roman, R.-C., Petriu, E.M., Hedrea, C., 2017, Tensor product-based model transformation for position control of magnetic levitation systems, Proc. 2017 IEEE International Symposium on Industrial Electronics, Edinburgh, UK, pp. 1141-1146.

74. Hedrea, E.-L., Precup, R.-E., Bojan-Dragos, C.-A., Roman, R.-C., Tanasoiu, O., Marinescu, M., 2018, Cascade control solutions for maglev systems, Proc. $201822^{\text {nd }}$ International Conference on System Theory, Control and Computing, Sinaia, Romania, pp. 20-26.

75. Hedrea, E.-L., Precup, R.-E., Bojan-Dragos, C.-A., Petriu, E.M., Roman, R.-C., 2019, Tensor product-based model transformation and sliding mode control of electromagnetic actuated clutch system, Proc. 2019 IEEE International Conference on Systems, Man, and Cybernetics, Bari, Italy, pp. 1418-1423.

76. Bojan-Dragos, C.-A., Hedrea, E.-L., Precup, R.-E., Szedlak-Stinean, A.-I., Roman, R.-C., 2019, MIMO fuzzy control solutions for the level control of vertical two tank systems, Proc. $16^{\text {th }}$ International Conference on Informatics in Control, Automation and Robotics, Prague, Czech Republic, vol. 1, pp. 810-817.

77. Hou, Z.-S., Wang, Z., 2013, From model-based control to data-driven control: Survey, classification and perspective, Information Sciences, 235, pp. 3-35.

78. Formentin, S., Karimi, A., Savaresi, S.M., 2013, Optimal input design for direct data-driven tuning of modelreference controllers, Automatica, 49(6), pp. 1874-1882.

79. Abouaïssa, H., Fliess, M., Join, C., 2017, On ramp metering: towards a better understanding of ALINEA via model-free control, International Journal of Control, 90(5), pp. 1018-1026.

80. Hou, Z.-S., Xiong, S.-S., 2019, On model-free adaptive control and its stability analysis, IEEE Transactions on Automatic Control, 64(11), pp. 4555-4569.

81. Van Waarde, H.J., Eising, J., Trentelman, H.L., Camlibel, M.K., 2020, Data informativity: a new perspective on data-driven analysis and control, IEEE Transactions on Automatic Control, DOI: 10.1109/TAC.2020.2966717.

82. Preitl, S., Precup, R.-E., Fodor, J., Bede, B., 2006, Iterative feedback tuning in fuzzy control systems. Theory and applications, Acta Polytechnica Hungarica, 3(3), pp. 81-96.

83. Preitl, S., Precup, R.-E., Preitl, Z., Vaivoda, S., Kilyeni, S., Tar, J.K., 2007, Iterative feedback and learning control. Servo systems applications, IFAC Proceedings Volumes, 40(8), pp. 16-27.

84. Precup, R.-E., Preitl, S., Rudas, I.J., Tomescu, M.L., Tar, J.K., 2008, Design and experiments for a class of fuzzy controlled servo systems, IEEE/ASME Transactions on Mechatronics, 13(1), pp. 22-35.

85. Roman, R.-C., Precup, R.-E., David, R.-C., 2018, Second order intelligent proportional-integral fuzzy control of twin rotor aerodynamic systems, Procedia Computer Science, 139, pp. 372-380.

86. Roman, R.-C., Precup, R.-E., Bojan-Dragos, C.-A., Szedlak-Stinean, A.-I., 2019, Combined model-free adaptive control with fuzzy component by virtual reference feedback tuning for tower crane systems, Procedia Computer Science, 162, pp. 267-274. 
87. Roman, R.-C., Precup, R.-E., Petriu, E.M., Dragan, F., 2019, Combination of data-driven active disturbance rejection and Takagi-Sugeno fuzzy control with experimental validation on tower crane systems, Energies, 12(8), 1548, pp. 1-19.

88. Nijmeijer, H., van der Schaft, A., 1990, Nonlinear Dynamical Control Systems, Springer-Verlag, Berlin, Heidelberg, New York.

89. Isidori, A., 1989, Nonlinear Control Systems, Springer-Verlag, Berlin, Heidelberg, New York.

90. Gartner, H., Astolfi, A., 1995, Stability Study of a Fuzzy Controlled Mobile Robot, Technical Report, Automatic Control Laboratory, ETH Zürich, Zürich, Switzerland.

91. Purcaru, C., Precup, R.-E., Iercan, D., Fedorovici, L.-O., David, R.-C., Dragan, F., 2013, Optimal robot path planning using gravitational search algorithm, International Journal of Artificial Intelligence, 10(S13), pp. 1-20.

92. Precup, R.-E., David, R.-C., Petriu, E.M., Szedlak-Stinean, A.-I., Bojan-Dragos, C.-A., 2016, Grey wolf optimizer-based approach to the tuning of PI-fuzzy controllers with a reduced process parametric sensitivity, IFAC-PapersOnLine, 49(5), pp. 55-60.

93. Precup, R.-E., David, R.-C., Szedlak-Stinean, A.-I., Petriu, E.M., Dragan, F., 2017, An easily understandable grey wolf optimizer and its application to fuzzy controller tuning, Algorithms, 10(2), 68, pp. 1-15.

94. Stavrou, D., Timotheou, S., Panayiotou, C.G., Polycarpou, M.M., 2018, Optimizing container loading with autonomous robots, IEEE Transactions on Automation Science and Engineering, 15(2), pp. 717-731.

95. Alvarez Gil, R.P., Johanyák, Z.C., Kovács, T., 2018, Surrogate model based optimization of traffic lights cycles and green period ratios using microscopic simulation and fuzzy rule interpolation, International Journal of Artificial Intelligence, 16(1), pp. 20-40.

96. Goli, A., Aazami, A., Jabbarzadeh, A., 2018, Accelerated cuckoo optimization algorithm for capacitated vehicle routing problem in competitive conditions, International Journal of Artificial Intelligence, 16(1), pp. 88-112.

97. Precup, R.-E., David, R.-C., 2019, Nature-inspired Optimization Algorithms for Fuzzy Controlled Servo Systems, Butterworth-Heinemann, Elsevier, Oxford, UK.

98. Osaba, E., Del Ser, J., Camacho, D., Bilbao, M.N., Yang, X.S., 2020, Community detection in networks using bio-inspired optimization: Latest developments, new results and perspectives with a selection of recent metaheuristics, Applied Soft Computing, 87, 106010.

99. Precup, R.-E., Preitl, S., 2005, On the stability and sensitivity analysis of fuzzy control systems for servo-systems, in Fuzzy Systems Engineering, Theory and Practice, Nedjah, N., Macedo Mourelle, L., Eds., Springer-Verlag, Berlin, Heidelberg, New York, Studies in Fuzziness and Soft Computing, vol. 181, pp. 131-161.

100. Preitl, S., Precup, R.-E., 1997, Introducere in conducerea fuzzy a proceselor, Editura Tehnica, Bucharest, Romania.

101. Galichet, S., Foulloy, L., 1995, Fuzzy controllers: synthesis and equivalences, IEEE Transactions on Fuzzy Systems, 3(2), pp. 140-148.

102. Preitl, S., Precup, R.-E., Kilyeni, S., 2000, State space approach to the stability analysis of a class of fuzzy control systems meant for third-order plants, IFAC Proceedings Volumes, 33(28), pp. 259-264.

103. Haber-Haber, R., Haber, R., Schmittdiel, M., del Toro, R.M., 2007, A classic solution for the control of a highperformance drilling process, International Journal of Machine Tools and Manufacture, 47(15), pp. 2290-2297.

104. Costin, H., Rotariu, C., Alexa, I., Constantinescu, G., Cehan, V., Dionisie, B., Andruseac, G., Felea, V., Crauciuc, E., Scutariu, M., 2009, TELEMON - A complex system for real time medical telemonitoring, Proc. $11^{\text {th }}$ International Congress of the IUPESM/World Congress on Medical Physics and Biomedical Engineering, Munich, Germany, pp. 92-95.

105. Pozna, C., Precup, R.-E., 2014, Applications of signatures to expert systems modeling, Acta Polytechnica Hungarica, 11(2), pp. 21-39.

106. Vaščák, J., Hvizdoš, J., Puheim, M., 2016, Agent-based cloud computing systems for traffic management, Proc. 2016 International Conference on Intelligent Networking and Collaborative Systems, Ostrava, Czech Republic, pp. 73-79.

107. Albu, A., Precup, R.-E., Teban, T.-A., 2019, Results and challenges of artificial neural networks used for decision-making in medical applications, Facta Universitatis-Series Mechanical Engineering, 17(4), pp. 285-308

108. Wang, X.-X., Xu, Z.-S., Gou, X.-J., Trajkovic, L., 2020, Tracking a maneuvering target by multiple sensors using extended Kalman filter with nested probabilistic-numerical linguistic information, IEEE Transactions on Fuzzy Systems, 28(2), pp. 346-360.

109. Precup, R.-E., Preitl, S., 2003, Development of fuzzy controllers with non-homogeneous dynamics for integraltype plants, Electrical Engineering, 85(3), pp. 155-168.

110. Precup, R.-E., Preitl, S., Balas, M., Balas, V., 2004, Fuzzy controllers for tire slip control in anti-lock braking systems, Proc. 2004 IEEE International Conference on Fuzzy Systems, Budapest, Hungary, 3, pp. 1317-1322. 
111. Anh, H.P.H., Ahn, K.K., 2011, Hybrid control of a pneumatic artificial muscle (PAM) robot arm using an inverse NARX fuzzy model, Engineering Applications of Artificial Intelligence, 24(4), pp. 697-716.

112. Michail, K., Deliparaschos, K.M., Tzafestas, S.G., Zolotas, A.C., 2016, AI-based actuator/sensor fault detection with low computational cost for industrial applications, IEEE Transactions on Control Systems Technology, 24(1), pp. 239-301.

113. Dzitac, I., Filip, F.-G., Manolescu, M.-J., 2017, Fuzzy logic is not fuzzy: World-renowned computer scientist Lotfi A. Zadeh, International Journal of Computers Communications and Control, 12(6), pp. 748-789.

114. Andoga, R., Főző, L., Judičák, J., Bréda, R., Szabo, S., Rozenberg, R., Džunda, M., 2018, Intelligent situational control of small turbojet engines, International Journal of Aerospace Engineering, 2018, 8328792, pp. 1-16.

115. Hedrea, E.-L., Precup, R.-E., Bojan-Dragos, C.-A., 2019, Results on tensor product-based model transformation of magnetic levitation systems, Acta Polytechnica Hungarica, 16(9), pp. 93-111. 